\title{
On cotarnina
}

\section{Wöhler}

To cite this article: M. Wöhler (1845) On cotarnina, Philosophical Magazine Series 3, 26:173, 362-364, DOI: $10.1080 / 14786444508645146$

To link to this article: http://dx.doi.org/10.1080/14786444508645146

$$
\text { 册 Published online: } 30 \text { Apr } 2009 .
$$

Submit your article to this journal 준

Q View related articles ¿ 
acquires a deep yellowish-red colour; this solution is to be supersaturated with hydrochloric acid, which precipitates the humopinic acid, resembling in appearance hydrated peroxide of iron. It is to be washed in alcohol, which leaves a light residue of a dull substance.

The alcoholic solution, when dropped gradually into water, forms with it an emulsion of a deep peach-red colour.

By evaporating the alcohol, the humopinic acid remains in the state of a deep brown mass.

The properties of humopinic acid are, that it is an amorphous substance of a deep brown colour. It melts when heated, and burns with flame, and emits an odour of narcotina. It is insoluble in weak acids and in water; the alcoholic solution is of a deep yellowish-red colour. The alkalies dissolve it, forming a saffron-coloured solution. These solutions give deep brown gelatinous precipitates, with the salts of lead and barytes. When this acid is long boiled in water, it becomes insoluble in ammonia, the alkalies and alcohol merely dissolve it with more difficulty, and always leave a blackish-brown insoluble substance, which resembles humin perfectly.

It appears by analysis to be composed of,-

Carbon ...... 64.4

Hydrogen .... $5 \cdot \mathbf{5}$

Oxygen...... $\frac{30.5}{100^{\circ}}$

Ann. de Ch. et de Phys., October 1844.

ANALYSIS OF THE METEORIC IRON OF GRASSE.

BY LE DUC DE LEVYNES.

The author states the following as the analyses hitherto published, which show the greatest quantity of nickel in various specimens of meteoric iron :-

Iron of Elbogen, by John, 8.75 per cent. Iron of Hradschina, [Agram] by Wehrle, $8 \cdot 88$; by Holger, $11 \cdot 84$. The Louisiana iron, by Shepard, 9.67. The Potosi, by Morren, 9.75. The Siberia, last analysis by Berzelius, 10·73. Iron from the Cape, by Tennant, 10; by Wehrle, 12:27. The iron from Claiborne, North America, by Jackson, $24 \cdot 70$ per cent.

The Grasse iron did not appear to contain either sulphur, silica or cobalt ; it yielded,-

$$
\begin{array}{cc}
\text { Iron } \ldots . . . . & 82 \cdot 63 \\
\text { Nickel } \ldots . . & \frac{17 \cdot 37}{100^{\circ}}
\end{array}
$$

It contained also traces of manganese and copper.-Annales des Mines, tome v. 161.

\section{ON COTARNINA. BY M, WÖHLER.}

This name is given by the author to a new organic base which is produced along with opianic acid; it contains azote and narcotina. It occurs in the mother-waters from which opianic acid is separated. In order to separate it from the sulphate of manganese and undecom- 
posed narcotina, the solution is to be heated to ebullition, and afterwards saturated with carbonate of soda, and the oxide of manganese precipitated is to be separated by filtration; the filtered liquid neutralized with hydrochloric acid is to be precipitated with chloride of platina, which forms a difficultly soluble compound with the new base, so that it may be washed with cold water; these precipitations must not, however, be made in solutions which are very dilute; the precipitation may also be effected by bichloride of mercury.

The author at first employed another method, but it is probable that a portion of the new base was decomposed by the excess of soda; it is, however, mentioned as probably serving to explain the formation of a body hereafter to be noticed.

The mother-waters above mentioned are to be much concentrated, so as to separate a large proportion of the salt of manganese; it is then, after filtration, to be treated with excess of carbonate of soda and evaporated to dryness. The dry mass treated with alcohol dissolves some substances which give it a deep brown colour, and the solution has a very bitter taste. The alcohol is afterwards evaporated, the syrupy residue is to be diluted with water and neutralized with a little hydrochloric acid, and then mixed hot with a solution of chloride of platina; on cooling the double salt is deposited in transparent mammillated masses of a reddish-yellow colour.

The double salt prepared in this manner could not contain any narcotina; excess of peroxide of manganese and sulphuric acid had been employed in the preparation; the ebullition of the mixture had been long continued, and the mixture had besides been treated with soda, so that ammonia did not precipitate any narcotina.

The narcotina [platina ?] was separated from this salt by powdering it and putting it into boiling water, into which sulphuretted hydrogen was passed. The yellow liquid which filters on separating the sulphuret of platina, retains hydrochlorate of cotarnina, and is afterwards treated with hydrate of barytes. It is then to be evaporated to dryness and treated with alcohol, which leaves carbonate of barytes and chloride of barium.

Cotarnina was obtained in the form of a radiated yellow mass. Water and alcohol dissolve it readily, and assume an intense yellow colour. It has a very bitter taste and a slightly alkaline reaction. When heated it fuses and carbonizes, emitting a disagreeable smell. The charcoal is difficult of incineration, but it burns without residue.

When dried after saturation with hydrochloric acid, it forms a yellow amorphous mass, in which crystalline nuclei are sometimes perceptible. The alkalies do not precipitate it from its solution in hydrochloric acid, but it is thrown down by the chlorides of mercury and platina, and by tannic acid.

The double salt of mercury is a bulky precipitate of a pale yellow colour, which soon becomes crystalline. In hot weak solutions no precipitation takes place, but on cooling, the salt is deposited in small pale yellow prisms. When attempts are made to recrystallize it, it appears to undergo some modification as to its composition.

The double salt of platina, formed in cold solutions, very much 
resembles the double chloride of ammonium and platina. When the solutions are mixed hot, it precipitates on the cooling of the mixture, and forms small transparent yellowish-red mammillated masses. This salt also seems to be modified when it is redissolved, and appears to contain ammonia. When it is boiled with barytes water, the base is decomposed and platina black is formed.

The author gives the following as the composition of cotarnina, reserving, however, a correction which may be required, as he was not quite sure that the substance was absolutely pure.

The platina salt gave,-

I.

Chlorine .. 24.07

Carbon .... 35.04

Hydrogen ... $\quad 3 \cdot 20$

Azote..... 4. 4.44

Oxygen .... 10:26

Platina .... $\frac{22.97}{99 \cdot 98}$
IJ.

$34 \cdot 35$

$3 \cdot 46$

$22 \cdot 64$
Equivalents. Calculation.

\begin{tabular}{rr}
3 & $24 \cdot 7$ \\
26 & $36 \cdot 3$ \\
14 & $3 \cdot 2$ \\
1 & $3 \cdot 3$ \\
5 & $9 \cdot 6$ \\
1 & $22 \cdot 9$ \\
\hline & $100^{\circ}$
\end{tabular}

The mercurial salt yielded-

Experiment. Equivalents, Calculation.

$\begin{array}{lrrr}\text { Chlorine.... } & 20.68 & 3 & 19.9 \\ \text { Azote ..... } & \mathbf{2 . 5 2} & 1 & 2.6 \\ \text { Carbon .... } & & 26 & \\ \text { Hydrogen . } & & 14 & \\ \text { Oxygen ... } & & 5 & \\ \text { Mercury... } & 37.95 & 2 & \end{array}$

The composition of cotarnina will then be $=\mathrm{C}^{20} \mathrm{H}^{19} \mathrm{NO}^{5}$;

The composition of the double salt of platina $=\overline{\mathrm{PtCl}^{2}}+\underline{\mathrm{HCl}}+\mathrm{co}$. tarnina ;

The composition of the double salt of mercury $=2 \mathrm{HgCl}+\underline{\mathrm{HCl}}+$ cotarnina.

The latter contains therefore one equivalent more metallic chloride than the former.-Ann. de Ch. et de Phys., October 1844.

\section{ON APOPHYLLENIC ACID. BY M. WÖHLER.}

The author has been unable to produce this substance with cer.. tainty, and he has not obtained sufficient to determine its composition; but some of its properties are so characteristic, that he does not hesitate to consider it as a peculiar substance, and to bestow a name upon it.

It contains azote ; it crystallizes in two different forms, when anhydrous and when hydrated; when it contains water of crystallization, it forms much-elongated octahedrons with a rhombic base, which cleave very readily parallel to their base, the cleavage face having a pearly lustre, exactly like the crystals of apopliyllite, whence the name given to this acid. They readily lose their water, but preserve their form and become opake; this happens below $212^{\circ}$, and the loss amounts to 9 per cent. 